\title{
Fabricating a Custom Clip for a Hader Bar Attachment: A Clinical Report
}

\author{
Kriti Mehrotra* \\ Department of Periodontics, Bapuji Dental College \& Hospital, India
}

Submission: May 24,2017; Published: June 07, 2017

*Corresponding author: Kriti Mehrotra, Department of Periodontics, Bapuji Dental College \& Hospital, Davangere, Karnataka 577004, India, Email: kriti1004@gmail.com

\section{Introduction}

The ultimate objective of prosthodontic management is to rehabilitate the patient to as nearly normal function as possible. DeVan's golden statement: "Perpetual preservation of what remains is more important than the meticulous replacement of what is missing" still rings true. So, a natural tooth supported overdenture remains a viable treatment option as it preserves the alveolar bone due to the healthy periodontal ligament around the retained teeth [1]. Several attachments have been used with overdentures: studs, magnets and bars of which bar and clip attachments have been one of the most common and versatile [2].

Bar attachments are more advantageous over other types owing to its splinting effect on the abutment teeth while eliminating need for parallel abutments and guiding the prosthesis in place. So, bar retained overdentures are the choice of treatment for most clinicians, but the only obstacle is its cost [3], leading to constant need for technical innovations to better the existing modalities in terms of their availability and expense. In the past, custom made hader bars using coffee straws [4] and custom made clips using gold alloys [2] have been tried in an endeavor to avoid the costlier prefabricated sophisticated semi precision attachments.

An efficient and a more inexpensive alternative has been accounted for in this case report for fabricating a custom made hader bar and clip attachment using toothpicks and Valplast flexible denture material respectively while utilizing the undercut of hader bar for retention and stability.

\section{Case Report}

A 33 year old lady patient reported to the Outpatient Department with chief complaint of replacement of her missing teeth. Intraoral examination revealed only remaining mandibular canines in the 3rd and 4thquadrant (33 \&43 respectively) and the first premolar in the 4thquadrant (44) and a resorbed residual ridge as seen in (Figure 1). She gave a history of periodontal disease leading to the loss of the remaining mandibular teeth. Owing to her poor periodontal status, she underwent complete periodontal non-surgical and surgical therapy for the remaining teeth. For replacement, various treatment modalities available and possible in her case were explained to her. The patient decided to go in for an option which offered improvement in masticatory ability but still would not overburden her financially. Keeping her age, periodontal health of remaining teeth and ridge form in consideration overdenture with the hader bar attachment was planned. Customized hader bar and clip attachment was attempted owing to her financial constraints.

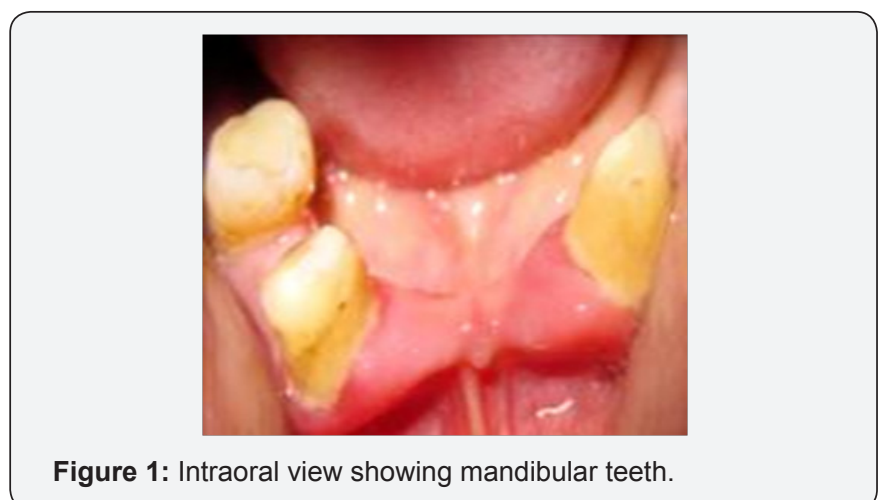

\section{Fabricating custom hader bar attachment}

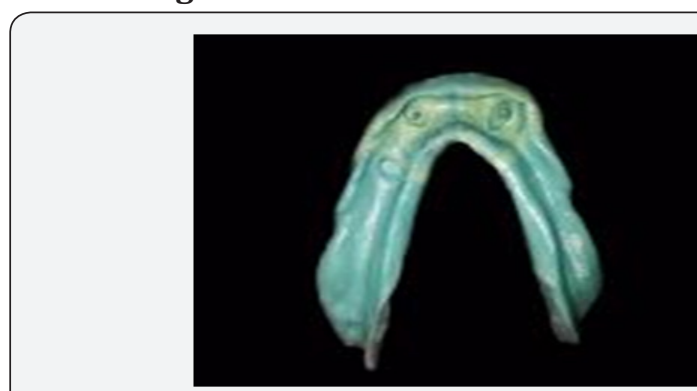

Figure 2: Impression of mandibular ridge \&post space taken with polyvinyl siloxane impression material. 


\section{Juniper Online Journal of Case Studies}

Elective endodontics was performed and post space was prepared in $33 \& 43$, keeping both the preparations parallel to each other so that a common path of insertion could be accomplished. Impression of post space and the mandibular ridge was made with polyvinyl siloxane as illustrated in (Figure 2) and a master cast was obtained from the impression.

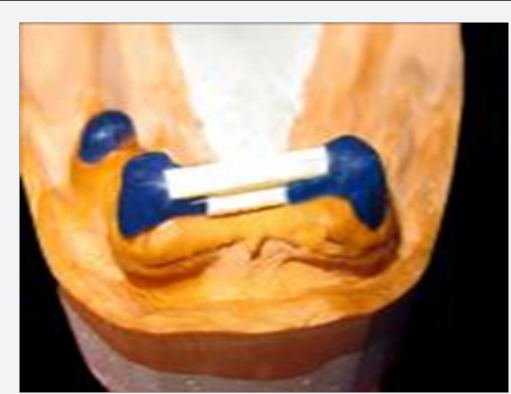

Figure 3: Hader bar pattern fabrication using pattern wax \& tooth picks.

On the master cast, the pattern for post was prepared using pattern resin and the coping was made over it using pattern wax. Two toothpicks with round cross section were adhered to each other using cyanoacrylate adhesive, so as to get figure of eight cross sections. One toothpick was cut into half and a flat base was achieved which faced the gingiva and the whole fabrication was attached to the two copings i.e. $33 \& 43$ as seen in (Figure 3). The whole assembly was invested, burnout and cast in cobalt chromium alloy, finished and polished. The casting was checked for a passive fit inside the patient's mouth as seen in (Figure 4). After that the casting was sealed on the master cast and a mould was fabricated from addition silicone laboratory model duplicating material. Two duplicated models were created, one for making custom clip and the other for fabrication of the denture.

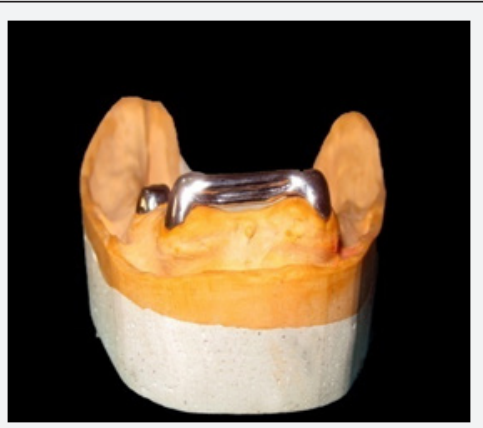

Figure 4: Casting of Hader bar

Fabrication of custom clip: On one of the duplicated cast, waxing for the clip, so as to engage minimal undercut of the bar was performed as illustrated in (Figure 5). Later it was processed, replacing the wax with Valplast flexible denture material as seen in (Figure 6).

Fabrication of denture: On the other duplicated cast the bar area was blocked out using dental plaster so as to make space for the self-cure acrylic resin and the custom made clip latter on.
Following the jaw relations records obtained from the patient, the cast was mounted on the articulator, teeth arrangement was done and the try-in was performed. Denture was then processed in the conventional way.

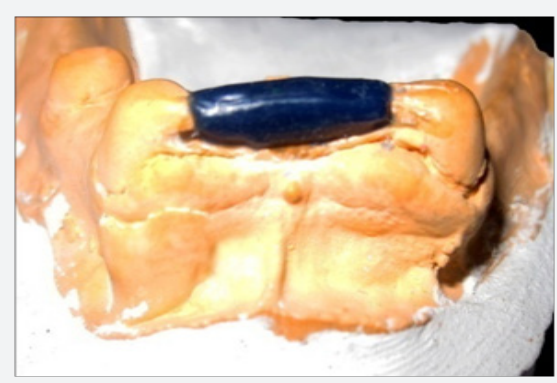

Figure 5: Waxing for clip to be duplicated with valplast

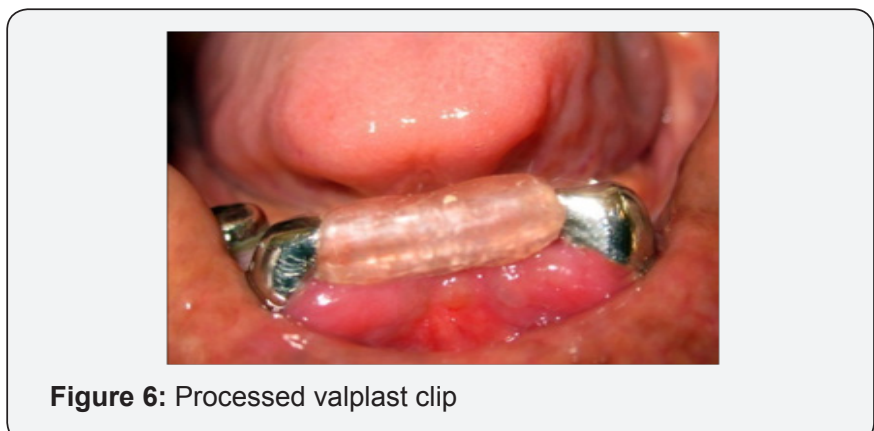

Denture and clip union: Later, the custom made clip was placed on the cast bar in the patient's mouth and a pickup of clip with self-cure acrylic resin was done with the processed denture as seen in (Figure 7). The self cure acrylic resin was placed only on the crest of the clip and self cure acrylic resin didn't cover the labial and lingual side of the clip as explained in (Figure 8).

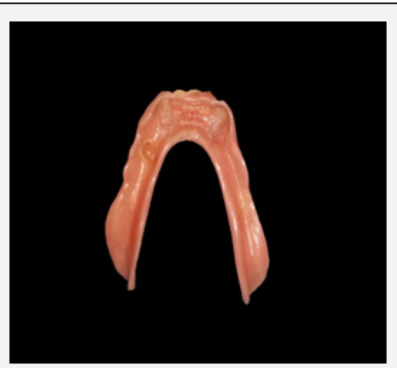

Figure 7: Pick up of valplast clip taken into the processed denture using self cure acrylic resin material

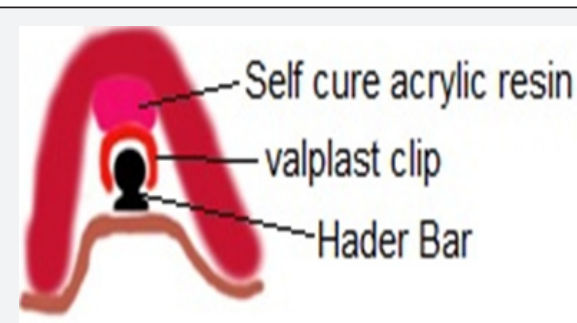

Figure 8: Diagrammatic illustration of custom made hader bar and clip attachment (Note the extension of self cure acrylic resin) 


\section{Summary}

In underdeveloped or developing economies, where patient's willingness to pay is very low, it is imperative that the clinician's utilize their knowledge to make sophisticated systems more economical. Therefore this article presents a case report for a young patient with partially edentulous lower jaw that was treated with a cost effective alternative to customized hader bar and clip attachment.

\section{References}

1. Carlsson GE (2004) Responses of jawbone to pressure. Gerodontology 21(2): 65-70.

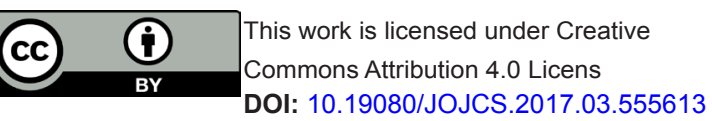

2. Bolouri A, Zartman RR (2006) Fabrication of custom clips for bar-andclip attachments for implant-supported over dentures. J Prosthet Dent 96(5): 379-380.

3. Mensor MC Jr (1978) Attachment fixation of the overdenture: part II. J Prosthet Dent 39(1): 16-20.

4. Guttal SS, Shetty US (2012) Coffee straw can replace Hader bar for bar retained overdentures--a clinical report. Eur J Prosthodont Restor Dent 20(4): 181-183.

\section{Your next submission with Juniper Publishers will reach you the below assets}

- Quality Editorial service

- Swift Peer Review

- Reprints availability

- E-prints Service

- Manuscript Podcast for convenient understanding

- Global attainment for your research

- Manuscript accessibility in different formats

( Pdf, E-pub, Full Text, Audio)

- Unceasing customer service

Track the below URL for one-step submission https://juniperpublishers.com/online-submission.php 